\title{
Disociación salud-economia: pertinencia de la reapertura económica en Colombia y su impacto en el manejo sanitario de la pandemia de covid-19
}

\author{
Health-economy dissociation: pertinence of the \\ economic reopening in Colombia and its impact on the \\ health management of the covid-19 pandemic
}

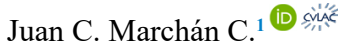

\begin{abstract}
Forma de citar: Merchán-C JC. Disociación salud-economía: pertinencia de la reapertura económica en Colombia y su impacto en el manejo sanitario de la pandemia de covid-19. Salud UIS. 53: e21028. doi: https://doi.org/10.18273/saluduis.53.e:21028 (c) (i)

Respetado editor,

El mundo pocas veces ha vivido una parada económica tan súbita como la generada por la pandemia de covid-19. En Colombia ha suscitado una crisis económica de grandes magnitudes; el desempleo ha aumentado, las empresas en crecimiento han quebrado, la demanda de algunos bienes y servicios mermó ${ }^{1}$. En respuesta a ello, el gobierno Colombiano puso en marcha la reapertura de todos los sectores productivos. Dicha iniciativa ha sido motivo de controversia, haciéndose popular la idea de una disociación entre la economía y la salud. En la mente de todos está imperante la necesidad de elegir solo un camino de la dicotomía: si procuramos la salud, la economía cae; si reabrimos la economía, los contagios y muertes aumentan. Pero, ¿Es real esa disociación? ¿Qué dice la evidencia sobre la relación salud-economía durante pandemias? ¿Qué opinan los expertos?
\end{abstract}

Tras analizar la evidencia histórica de la pandemia de gripe Española de 1918, es posible afirmar que la disociación salud-economía es una falacia. Tras esta pandemia, la recuperación económica fue más rápida en aquellas comunidades que iniciaron tempranamente las medidas de salud pública y aislamiento social preventivo, ya que se disminuyeron gastos de hospitalización y los sobrevivientes apoyaron la reactivación económica² ${ }^{2}$ Pero, también hay evidencia de que gran parte de los decesos ocurridos se debieron al hambre y la escasez de alimentos, y la mayoría correspondieron a personas de estratos socioeconómicos bajos, que fueron las más fuertemente golpeadas por la caída económica ${ }^{3}$.

1. Universidad del Norte. Barranquilla, Colombia.

Correspondencia: Juan C Marchán. Dirección: Carrera 62, Calle 48-78 Barranquilla. Teléfono: +60 (5) 318 2144. Correo electrónico: marchanj@uninorte.edu.co 
Por otro lado, según el DANE, luego de casi 12 meses de contracción económica, en el primer trimestre del 2021 se evidenció por primera vez una expansión real de la economía colombiana, con un aumento del 1,1\% del PIB. Desde la dirección de esta entidad afirman que dicha mejoría se debe al levantamiento de las cuarentenas estrictas iniciadas por el gobierno nacional en 2020, que a finales de ese año dejaron una caída de $6,8 \%$ del PIB ${ }^{4}$. Además, algunos expertos aseguran que la reapertura es pertinente, ya que el virus seguirá estando presente y como sociedad no podemos continuar encerrados; sugieren que para no afectar la salud con la reapertura económica, la cuarentena debe ser obligatoria para los casos positivos y sus convivientes, también proponen mantener el uso de elementos de protección personal y realizar reformas que mejoren la formalidad del mercado laboral, al empleabilidad y la educación ${ }^{5}$.

La evidencia es clara y deja manifiesto que la salud y la economía, durante las pandemias, se comportan como factores intersectados, con repercusión recíproca. Si se mantienen medidas preventivas básicas (lavado de manos, distanciamiento social y uso de mascarilla), y se flexibilizan las medidas más restrictivas como confinamientos, la recuperación económica será más eficiente; y al recuperar la economía, las muertes y los factores agravantes de la pandemia, serán menores.

En varios países la reapertura es mucho más sencilla, ya que cuentan con mejor vigilancia epidemiológica, oferta hospitalaria y de UCI, más agilidad en la vacunación, empoderamiento comunitario y apoyo económico a los más necesitados. Este no es el caso de Colombia, por eso la reapertura será gradual, primero en las ciudades que tienen menos casos activos de covid-19, menor ocupación de UCI y mayores tasas de inmunización (natural o artificial). Además, se mantienen las medidas preventivas básicas.

El médico colombiano está llamado a hablar de la reapertura económica y debe tener una posición clara, objetiva (basada en la evidencia) y no pasional sobre la pertinencia de la misma. De esta manera, confiando en el autocuidado, la responsabilidad ciudadana y el crecimiento exponencial de la vacunación, le puede dar un voto de fe a la reapertura gradual.

Finalmente, si bien la selección natural y la dinámica cultural de las poblaciones son los determinantes fundamentales para la aparición de nuevos virus y el origen de las pandemias, el deterioro ambiental y la desigualdad social son factores que ponen al ser humano en condición de vulnerabilidad ante tales amenazas emergentes. Por eso el sentido de la reapertura económica debe cambiar, no es viable volver a lo mismo; el estado debe hacer efectivas las políticas públicas encaminadas a la igualdad social y ser gestor de un cambio ambiental sin precedentes; solo así el efecto de la reapertura económica será atemporal y nuestra economía estará hecha a prueba de pandemias.

\section{Referencias}

1. Morales L, Bonilla L, Pulido J, Flórez L, Hermida D, Pulido K et al. Efectos de la pandemia por Covid-19 en el mercado laboral colombiano: identificando el impacto de las restricciones sectoriales a la movilidad. Banco de la República. 2020. https://www.banrep.gov.co/es/borrador-1129

2. Correia S, Luck S, Verner E. Pandemics Depress the Economy, Public Health Interventions Do Not: Evidence from the 1918 Flu. SSRN. 2020.

3. Martini M, Gazzaniga V, Bragazzi NL, Barberis I. The Spanish Influenza Pandemic: a lesson from history 100 years after 1918. J Prev Med Hyg. 2019; 60(1): E64-E67. doi: 10.15167/2421-4248/jpmh2019.60.1.1205

4. DANE. Comunicado de prensa Producto Interno Bruto (PIB) IV trimestre y año 2020. Bogotá - Colombia; 2021.

5. División de Análisis Macroeconómico. Impacto De la pandemia Covid-19 sobre el mercado laboral en Colombia: el papel del empleo en la recuperación económica. http://www.fce.unal.edu.co/centro-editorial/documentos/ escuela-de-economia/2646-111-impacto-de-la-pandemia-covid-19-sobre-el-mercado-laboral-en-colombia-elpapel-del-empleo-en-la-recuperacion-economica.html 